\title{
CORRESPONDENCE
}

Insulin: U40, U80, or U100?

Joanna Sheldon, FRCP, and others.......1319

Coronary artery disease and coalworkers' pneumoconiosis

W R Parkes, MD, and others.........1319

The London hospitals scene

$J$ Forsythe, FFCM, and others; Sir

Francis Avery Jones, FRCP............ 1320

Community physicians and

administrators

P MacMahon, FHA.............1321

Percutaneous transhepatic

cholangiography

G M Fraser, FRCR, and others. . . . . 1321

Training in practice

C J R Hart, MRCGP; Margaret Thomson

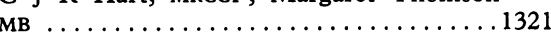

Reactions to current influenza vaccine

M S Hall, MB; D K Payler, MRCP.......1322

Is there a future for community medicine?

K Papas, MD; S Hagard, DPH; N H N

Mills, MFCM..................... 1322

Angiotensin II blockade with saralasin

G A MacGregor, MRCP; R Beckerhoff, MD . .1323
Incomplete NHS prescriptions

G C Robinson, MPS ............... 1323

\section{White coat}

R MacG Aitken, FRCGP; G C Hancock, MB . . 1324

Plasma propranolol levels in coeliac disease and Crohn's disease

R E Schneider, FRCPED, and others...... 1324

Treatment of cervical spondylosis

P Harris, FRCSED; J H Cyriax, MD . . . . . . . 1324

Prostatic cancer

E P N O'Donoghue, FRCS, and G D

Chisholm, frCs................. 1324

Student health

D G Illingworth, FRCPED . . . . . . . . 1325

Promotion of new drugs on television

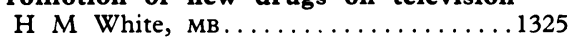

Aortic incompetence in systemic lupus erythematosus

A J IsAaCs, MRCP . . . . . . . . . . . 1325

Appointments in community medicine

R B Robinson, MFCM...............1325

General practitioners and coronary care

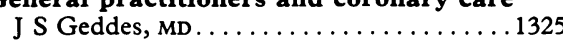

The elderly in a coronary unit

R G Simpson, FRCP.............. 1325
Managing mild hypertension

A Martin, MD .................... 1326

Confidence and medical appointments

H Caplan, FRCPATH................ 1326

Junior hospital doctors and Europe

P McNally, Frcs............... 1326

Health Service charges

P J E Wilson, fRCs.............1326

Industrial action and the Royal

Commission

P R B Pedlow, frcog. . . . . . . . . . 1327

Evidence to Royal Commission

A R Rogers, MB................ 1327

NHS superannuation and war service

W H Bond, FRCS; M H Hughes, FRCPATH . 1327

The $£ 8500$ limit

D C Evered, mD................ 1328

Points from letters Metoclopramide and prolactin (K D Jones); Postmenopausal urinary symptoms and hormonal replacement therapy (D Freedman); Ankylosing vertebral hyperostosis: unusual presentation (Jennifer $M$ Hunter); Postcoital contraception (Ishbel M Monks); Carcinoma of vulva in twin sisters (A $\mathrm{K}$ Ghosh) $\ldots \ldots \ldots \ldots \ldots \ldots \ldots \ldots \ldots \ldots \ldots \ldots$
Correspondents are urged to write briefly so that readers may be offered as wide a selection of letters as possible. So many are being received that the omission of some is inevitable. Letters should be signed personally by all their authors.

\section{Insulin: U40, U80, or U100?}

SIR,-Mistakes in insulin dosage arise all too frequently from confusion between units of insulin and marks on the insulin syringe and sometimes from changes in the strength of insulin prescribed. In a small survey carried out in the United States in 1967 no less than $50 \%$ of diabetics were making some error in insulin dosage, largely due to the use of different strengths of insulin. ${ }^{1}$ To overcome such mistakes the different strengths of insulin are being replaced in the US and Canada by a single strength-namely, $100 \mathrm{U} / \mathrm{ml}$ (U100). Syringes designed in the US for use with U100 insulin are graduated in units rather than in multiples of units.

The British Diabetic Association has recently completed a small, simple, multicentre trial of U100 insulin to assess its acceptability to diabetics in Britain. U100 insulin was supplied by the British insulin manufacturers as soluble, isophane, and lente. Syringes were either of $1.0-\mathrm{ml}$ or $0.35-\mathrm{ml}$ capacity. The $1.0-\mathrm{ml}$ syringes were either graduated at $1-U$ increments, or at $2-U$ increments, with a numerical designation at each $10-\mathrm{U}$ graduation; the $0.35-\mathrm{ml}$ syringes were graduated at $1-U$ increments.

One hundred and ten adult diabetics used U100 insulin for one month, $48 \%$ having previously used U40 insulin and 52\% U80 insulin. Many patients used mixtures of insulin and six patients had to measure $6 \mathrm{U}$ or less of one sort of insulin. Of patients previously using U40 insulin $52 \%$ preferred U $100,29 \%$ had no preference, and $19 \%$ preferred U40. Of patients previously using
U80 insulin $64 \%$ preferred U100, $21 \%$ had no preference, and $15 \%$ preferred U80.

About half of the patients preferred the BS1619 insulin syringe to their new syringe, but this was largely because of minor features of design in the new syringes which could easily be improved. The $1.0-\mathrm{ml}$ syringe graduated at $1-U$ increments was unsatisfactory because the graduations were too close together, but only three of 70 patients using the $1 \cdot 0-\mathrm{ml}$ syringe graduated at $2-U$ increments or the $0.35-\mathrm{ml}$ syringe had this problem. None of the six patients measuring $6 \mathrm{U}$ or less had any difficulty in accurate measurement of these small doses.

There were no significant changes in diabetic control when switching to U100 insulin except in three patients who calculated their dose as if they were using a BS1619 insulin syringe, which underlines the importance of careful instruction when changing to a syringe graduated for units of insulin.

Thus $83 \%$ of diabetics either preferred U100 insulin or had no preference; U100 insulin was found to be consistent with accurate measurement of small doses, as has been reported in American trials, ${ }^{2}$ and minimises the volume of injection.

A disadvantage of adopting U100 insulin in Britain is that at present other European countries are not in favour of doing so. This is largely because in other European countries about $90 \%$ of diabetics on insulin use U40 so that problems from having two strengths available are apparently rare. In Britain, however, about half the diabetics on insulin use $U 40$ and half $U 80$. We feel that our present system is unsatisfactory and that a single strength of insulin for general use is desirable even though other strengths may very occasionally be required. We would recommend the withdrawal of U40 and U80 insulins and their replacement by U100 insulin, which this trial suggests would be preferred by diabetics. $\begin{array}{ll}\text { JOANNA SHELDON (Brighton) } & \text { K J GURLING } \\ \text { D M HILI } & \text { T R E PILKINGTON } \\ \text { BRIAN F BREARIEY } & \text { T M HAYES } \\ \text { P EDWARD DIPPLE } & \text { PETER SONKSEN } \\ \text { ARNOLD BLOOM } & \text { T D R HOCKADAY }\end{array}$ ARNOLD BLOOM T D R HOCKADAY

'Watkins, J D, et al, American fournal of Public Health, $1967,57,452$.

Rosenbloom, A L, et al, Physicians Drug Manual, $1971,2,142$.

Coronary artery disease and coalworkers' pneumoconiosis

SIR,-Though the arguments offered for debate by Dr Dewi Davies's article (16 October, p 925) are numerous, they come down to this: in his view the opinions given by the Pneumoconiosis Medical Panel doctors in cases of death from coronary artery disease in coalminers with advanced pneumoconiosis are "irrational and based on entirely faulty deductions" and therefore, by implication, would seem to be at odds with generally received medical knowledge. The fundamental point at issue is whether the occurrence of myocardial infarction and of sudden death due to cardiac arrest or ventricular fibrillation following infarction is significantly more (or less) probable in the presence of advanced progressive massive fibrosis (PMF) or other chronic lung disease than in their absence. By sudden death we mean death occurring instantaneously or within minutes or hours. 
Death from myocardial infarction in the general population is at its highest in the fourth, fifth, and sixth decades, whereas death among men with PMF (ILO $x$-ray categories $B$ and $C$ ) occurs mainly in the sixth and seventh decades. There is, as far as we know, no evidence that advanced chronic lung disease is associated with a higher than average death rate from ischaemic heart disease. On the contrary: for example, the standard mortality ratio for ischaemic heart disease in nonworking coalminers (some of whom would be expected to have severe respiratory disease) in the Appalachian mining states in the USA is the same as in the population at large ${ }^{1}$; and acute myocardial infarction is significantly less common in the presence of chronic obstructive lung disease than in its absence. ${ }^{2} 3$

In patients with advanced PMF impairment of lung function is common and a variable level of hypoxaemia is present at rest in many but not all cases and on effort in most. In contrast, pulmonary hypertension occurs in only a proportion. ${ }^{4}$ With regard to the effects of hypoxaemia upon the heart Dr Davies states that, although chronic cor pulmonale improves intercoronary anastomoses, "the greatest stimulus" to this is coronary atheroma, and he quotes Zoll et al as his authority. However, these authors demonstrated that "cardiac anoxia of various origins may ... stimulate interarterial anastomoses without necessarily [authors' emphasis] progressing to the stage of irreversible tissue damage." Seemingly there was no evidence that any one factor causing anoxia is superior to another in promoting anastomoses. Chronic hypoxaemia causes dilatation of the coronary arteries ${ }^{6}$ and coronary artery blood flow is not impaired in patients with emphysema and cor pulmonale. ${ }^{7}$ Furthermore, vascularisation of the myocardium is significantly greater in people living their lives in chronic hypoxia at high altitudes than in those at sea level.

Dr Davies asserts that "hypoxaemia may also increase the risk of severe arrhythmia." But in their authoritative work Extrasystoles and Allied Arrhythmias Scherf and Schott ${ }^{9}$ state that among the phenomena which precipitate ectopic arrhythmias hypoxia of a circumscribed area of the heart is of paramount importance and that while general hypoxia of the heart "cannot be regarded as playing a significant role in the causation of ectopic arrhythmias, by contrast regional ischaemia [authors' emphasis] is a very important factor" (p 948). And, of course, myocardial infarction causes regional ischaemia. Although hypoxaemia apparently increases the extent and severity of ischaemic injury in experimental coronary artery occlusion in dogs, ${ }^{10}$ ectopic arrhythmias precipitated by topical application of aconitine are suppressed or reduced by hypoxia $^{9}$ and the ventricular fibrillation threshold is unaffected by hypoxia with $\mathrm{PaO}_{2}$ reduced to $30 \%{ }^{11}$ Hence it would seem that chronic hypoxia due to chronic lung disease is unlikely to contribute to the development of ventricular fibrillation in myocardial infarction.

Dr Davies also says that "prospective surveys have shown that the existence of impaired lung function ... increases the risk of developing myocardial infarction." But this is not the impression given by the authors he quotes as evidence for this contention. Firstly, Tibblin et al, ${ }^{12}$ who used the peak expiratory flow rate (PEFR) in their study and found that only two of 19 men who died of ischaemic heart disease had values "above the median for the entire study population," concluded that "this factor (that is, impairment of lung function as measured by PEFR) was insignificant as a predictor of ischaemic heart disease." Secondly, Friedman $e$ al $^{13}$ stated that the level of "vital capacity cannot be considered an established risk factor in coronary disease," and airways obstruction was unrelated.

We submit, Sir, that the evidence of reported clinical, epidemiological, post-mortem, and experimental studies indicates that advanced PMF or other chronic lung disease capable of causing chronic hypoxia do not increase the likelihood of sudden death occurring from coronary artery disease or myocardial infarction.

\section{W RAYMOND PARKES T PHILlips \\ R G B Williamson}

Pneumoconiosis Medical Panel,

London

Costello, J, Ortmeyer, C E, and Morgan, W K C, Chest, 1975, 67, 417.

Mitchell, R S, Walker, $\mathrm{S} \mathrm{H}$, and Maisel, J C, American Review of Respiratory Diseases, 1968, 98, 611

Samad, I O, and Noehren, T H, Diseases of the Chest,

$1965,47,26$.
arratil, M, Widimsky, J, and Kasalicky, J, Bulletin
Physiopathol Resp (Nancy), 1968, 4, 349. Zoll, P M, Wessler, S, and Schlesinger, M J, Circulation, 1951, 4, 797.

Keele, C A, and Neil, E, Samson Wright's Applied Physiology, 12th edn, p 141. London, Oxford

University Press, 1971 . D L, Circulation Research,
Rose, L B, and Hoffman, D L,

1956, 4, 130 .
"Arias-Stella, J, and Topilsky, $M$, in High Altitude Physiology: Cardiac and Respiratory Aspects, ed $\mathrm{R}$ Porter and J Knight, $\mathrm{p}$ 149. Edinburgh and London, Churchill Livingstone, 1971 . Scherf, D, and Schott, A, Extrasystoles and Allied
Arrhythmias. London, Heinemann Medical, 1973. Radvany, P, Maroko, P R, and Braunwald, $\mathrm{E}$
American fournal of Cardiology, 1975, 35, 795. Turnbull, A D, et al, Fournal of Thoracic and Cardiovascular Surgery, 1965, 50, 843.

Tibblin, G, Wilhelmsen, L, and Werko, L, American Journal of Cardiology, 1975, 35, 514.

Friedman, G D, Klatsky, A L, and Siegelaub, A B,
New England Journal of Medicine, 1976, 294, 1071.

\section{The London hospitals scene}

SIR,-We were interested to read Sir Francis Avery Jones's article (30 October, p 1046) and $\mathrm{Mr}$ R S Murley's letter (13 November, $p$ 1192) on the deliberations of the Resource Allocation Working Party. The matters that they mention were discussed at length many times. However, the above writers have neglected one major constraint in the working party's remit. It should not be the function of the Health Service to correct the deficiencies of housing, social services, employment, environmental services, etc. It would otherwise be too easy for the appropriate central or local authority to abrogate its responsibility to correct the factors which underlie the cause of many of the disabilities and diseases for which care has to be provided by the Health Service. It is for this reason that we chose a health outcome measure which clearly is the resultant of the social and environmental conditions to which the population is exposed.

We also felt very strongly that it was the duty of ministers and authorities to plan and manage services-we should not attempt to pre-empt the management decisions of regions, areas, or districts in deciding what hospital or other facilities should be provided for the population of a particular locality. It was for this reason that we explained in our report ${ }^{1}$ that our remit was concerned with the distribution of money to provide services and not with what is done with it.

The terms of reference of the working party were to establish "a method of securing, as soon as practicable, a pattern of distribution responsive objectively, equitably and efficiently to relative need." The method we have recommended is to adopt as objective as possible a measure of health care needs in calculating "targets" as a yardstick for authorities and ministers to use in determining the actual allocation of financial resources. We stressed in deciding on the pace of any change towards "targets" they would need to take into account a variety of local factors such as those to which Sir Francis and $\mathrm{Mr}$ Murley refer. Of course we all hope that the formula will be refined as more reliable and quantifiable indicators are developed.

Kent Area Health Authority

J M FORSYTHE

Department of Community Medicine W W HOLLAND St Thomas's Hospital Medical Schoo

North-western Regional Health

A J LANE

Authority

(Medical Members of Resource Allocation Working Party)

\section{Department of Clinical Epidemiology \\ and Social Medicine, \\ St George's Hospital Medical School, London SW 17} A E BENNETT

Avon Area Health Authority ( $T$ )

A H SNAITH

Subcommitteal Members of Allocation Working Party)

'Department of Health and Social Security, Sharing
Resources for Health in England. London, HMSO, 1976.

SIR,-In "The London hospitals scene" (30 October, p 1046) I commented on the fallacies of the regional redistribution of resources. Since then figures are coming through on the effects of the Resource Allocation Working Party (RAWP) within London regions. I note that Brent and Harrow Area Health Authority's annual review will fall $24 \%(f 6 \mathrm{~m})$ for their target allocation. Camden and Islington's will plummet $30 \%(£ 18 \mathrm{~m})$ and City and East London's will go down a mere $15 \%$ ( $f 10 \mathrm{~m})$. With such losses of purchasing power there must be closure of major hospitals (perhaps Central Middlesex and Northwick Park Hospitals should spin a coin). At least four if not five London teaching hospitals will be snuffed out. Dr Horace Joules, whose splendid letter (20 November, p 1251) will be enjoyed by all his former colleagues, may be alone in his rejoicing.

If London is to be carved up without an anaesthetic the least the DHSS can do is to use a sharp knife and not the horribly blunt instrument devised by RAWP. Their use of mortality to measure morbidity, their failure to tackle social deprivation, and varying market costs will ensure the maximum pain and minimum justice.

Even so London could survive, as it did the blitz. What would not survive is our great medical national asset-centres of excellence which every year bring 3000-4000 overseas postgraduates seeking our expertise and returning to their countries, many later to give us export orders for our medical and hospital equipment. The RAWP report ${ }^{1}$ says, "There is no escaping the fact that one centre's 'excellence' may be bought at the expense of another's 'deprivation'" ( $p$ 47). What a miserable philosophy "for the leading medical country in the world!

Our national average is still far too low as 